\title{
Evaluation of a Fungal Strain, Myrothecium roridum F0252, as a Bioherbicide Agent
}

\author{
Hyang Burm Lee ${ }^{1 *}$, Jin-Cheol Kim², Kyung-Sik Hong² and Chang-Jin Kim ${ }^{3 *}$ \\ ${ }^{1}$ Division of Applied Bioscience \& Biotechnology, Chonnam National University, Gwangju 500-757, Korea \\ ${ }^{2}$ Korea Research Institute of Chemical Technology, Daejeon 305-600, Korea \\ ${ }^{3}$ Korea Research Institute of Bioscience \& Biotechnology, Daejeon 305-806, Korea
}

(Received on June 30, 2008; Accepted on August 27, 2008)

In the course of in vitro and in vivo screening for bioherbicidal agents, a hyphomycete fungus, Myrothecium sp. F0252 was selected as a candidate for the biocontrol of weeds. The isolate was identified as Myrothecium roridum Tode ex. Fries based on the morphological characteristics and $18 \mathrm{~S}$ ribosomal DNA sequence analysis and registered as Myrothecium roridum F0252. In order to evaluate the in vitro effect of $M$. roridum F0252 on germination of ladino clover and white clover (Trifolium repens $L_{\text {.) }}$ seeds, spore solution of the fungus was employed in two concentrations, $6.5 \times 10^{6}$ and $2.5 \times$ $10^{7}$ spores per $\mathrm{mL}$ and then inoculated to the seeds. The fungal spores inhibited the seed germination, infected the seedlings, and caused an abnormal withering and inhibition of seedling growth. In addition, when the herbicidal activity of crude ethyl acetate extract from the liquid culture was assessed on a mini-plant, duckweed (Lemna paucicostata (L.) Hegelm.), the extract showed high inhibitory effect at the level of $12.5 \mu \mathrm{g}$ per $\mathrm{mL}$. On the other hand, in vivo herbicidal activity of $M$. roridum F0252 was evaluated by a whole plant spray method. $M$. roridum F0252 exhibited strong and broadspectrum herbicidal activity. The herbicidal values ranged from 95-100\% against 7 weeds, including Abutilon avicennae and Xanthium strumarium, and 70-80\% against Digitaria sanguinalis and Sagittaria pygmaea. When the nutritional utilization (95 carbon sources) pattern of $M$. roridum F0252 was investigated, it varied with water activity $\left(a_{w}\right)$ and temperature conditions, supplying good, basic information in regard to nutritional utilization for proper cultivation and formulation. Our results showed that $M$. roridum F0252 might be used as a potential biocontrol agent against weedy plants.

Keywords : biocontrol agent, bioherbicidal potential, Myrothecium roridum

\footnotetext{
*Corresponding authors.

HB Lee. Phone) +82-62-530-2136, Fax) +82-62-530-2139

E-mail)hblee@jnu.ac.kr

C-J Kim. Phone) +82-42-860-4332, Fax) +82-62-860-4595

E-mail: changjin@kribb.re.kr
}

Weeds are an ever-present and an increasingly significant constraint to agricultural production worldwide. The overall impact of weeds on crop production can be crudely calculated, with average losses varying from 10-20\% (Evans et al., 2001). Current production levels can only be maintained through the regular and wholesale application of pesticides, particularly of chemical herbicides, which account for almost $50 \%$ of the agrochemical market (Woodburn, 1995). Chemical control has been internationally accepted but usage is restricted by the fact that effective weed herbicides can often affect many other plants, not to mention current public concern regarding environmental problems associated with chemical pesticide usage in general (Defago et al., 2001).

Biocontrol agents (BCAs) have been recognized not only as a replacement for chemical pesticides, but also as a viable part of well designed, integrated weed management systems, utilizing living organisms or plant pathogens to control or reduce the population of undesirable weed species (Charudattan, 1991, 2001; Christy et al., 1992; MullerScharer et al., 2000). Biological weed control is an approach utilizing living organisms to control or reduce the population of an undesirable weed species (Watson, 1991). Today, there has been a rising interest in exploitation of fungi for control of weeds and crop diseases (Butt et al., 2001). Currently, worldwide about 15-20 weeds are biologically controlled with pathogens (Rosskopf et al., 1999) and, to date, only two bioherbicides have been commercially registered for weed control, both in the United States. The bioherbicide DeVine ${ }^{\circledR}$, a liquid formulation of Phytophthora palmivora, was registered in 1981 for control of stranglervine (Morrenia odorata) in Florida citrus groves. Another bioherbicide, Collego ${ }^{\circledR}$, a dry powder formulation of Colletotrichum gloeosporioides f. sp. aeschynomene, was registered in 1982 for control of Northern Jointvetch (Aeschynomene virginica) in rice and soybeans in Arkansas, Louisiana, and Mississippi.

It has been known that approximately 8 Myrothecium species, including $M$. gramineum, $M$. roridum, and $M$. verrucarium, have been reported worldwide. The fungus 
could effectively control several common weeds under field conditions and shows potential as an effective bioherbicide for weed control in crop production systems (Boyett et al., 2007). Of these Myrothecium species, mainly M. verrucaria has been studied as a potential biocontrol agent for control of, for example, invasive climbing fern (Lygodium microphyllum), dandelion (Taraxacum officinale) (Clarke et al., 2007), kudzu (Boyette et al., 2002), and amaranth weeds including A. hybridus, A. spinosus, and A. lividus (Yang and Brenner, 1997) on the basis of their pathogenicity to host. Recent studies suggest that some Myrothecium species may serve as broad-spectrum bioherbicides (Walker and Tilley, 1997). It has been known that M. roridum may be very opportunistic and may cause severe damage to leaves and stems. Kathleen et al. (2004) reported that symptoms of infection on sicklepod develop very rapidly and that its mode of action is generally due to the activity of toxins, several of which are known to be produced by Myrothecium spp. As mentioned above, a significant number of host derived Myrothecium isolates have been collected as phytopathogens and applied as BCAs using their virulence and toxicity. In the study, the toxic activity of crude harvests of $M$. verrucaria was not diminished after the removal of fungal mycelium and spores. In contrast, conidia preparations showed relatively little impact on weed species (Boyett et al., 2007; Kathleen et al., 2004).

Recently, we have also isolated several Myrothecium species from soil samples and attempted to evaluate their potential as BCAs for weeds. To our knowledge, this appears to be the first attempt to use a non-host derived fungal species, M. roridum, to control weeds in Korea. This aim of this work was to evaluate the in vitro and in vivo bioherbicidal activity of $M$. roridum F0252 against various weed and crop plants, and to investigate the impact of basic environmental factors, such as water activity $\left(a_{v}\right)$ and temperature, on mycelial growth and nutritional utilization of carbon sources of the fungus.

\section{Materials and Methods}

Fungal isolation and identification. About 1,000 fungal isolates were isolated from diverse soil samples from different districts of Korea using a dilution plating method and were first screened for bioherbicidal activity in vitro using Lemna, and clover seedlings as described below. An active fungus, Myrothecium sp. F0252 was isolated from a paddy soil sample from Kongju, Chungnam Province, Korea. The medium used for fungal isolation was potato dextrose agar (PDA, Difco) and the active fungus was identified as Myrothecium roridum Tode ex Fr. based on the morphological and culture characteristics of phialoconidia, conidia and sporodochia (Domsch and Gams, 1980; Ellis, 1971;
Preston, 1961), and the sequence analysis of internal transcribed spacer (ITS) region of 18S rRNA. The molecular characterization of the isolate was performed according to previous published methods (Lee et al., 2005, 2006). The isolate has been deposited in KRIBB (KCTC 0980BP), Daejeon, Republic of Korea, and EML herbarium, Chonnam National University, Gwangju, Republic of Korea and named as Myrothecium roridum F0252, holding the isolate under lyophilized conditions and $20 \%$ glycerol at $-80^{\circ} \mathrm{C}$. The isolate was also maintained at refrigerator $\left(2-3^{\circ} \mathrm{C}\right)$ until used for cultivation.

Lemna bioassay. A mini-plant, duckweed (Lemna paucicostata (L.) Hegelm.), grown on 24 well plate (Corning Co., New York, USA) filled with $20 \%$ Hutner's nutrient medium consisting of (in mg L ${ }^{-1}$ ) $\mathrm{NH}_{4} \mathrm{NO}_{3} 200, \mathrm{~K}_{2} \mathrm{HPO}_{4}$. 400, $\mathrm{KOH} 200, \mathrm{Ca}\left(\mathrm{NO}_{3}\right)_{2} \cdot 4 \mathrm{H}_{2} \mathrm{O} 354, \mathrm{MgSO}_{4} \cdot 7 \mathrm{H}_{2} \mathrm{O} 100$, $\mathrm{FeSO}_{4} \cdot 7 \mathrm{H}_{2} \mathrm{O} 24.9, \mathrm{MnCl}_{2} \cdot 4 \mathrm{H}_{2} \mathrm{O} 17.9, \mathrm{ZnSO}_{4} \cdot 7 \mathrm{H}_{2} \mathrm{O} 3.95$, $\mathrm{H}_{3} \mathrm{BO}_{3}$ 14.2, $\mathrm{Na}_{2} \mathrm{MoO}_{4} \cdot 2 \mathrm{H}_{2} \mathrm{O}$ 25.2, $\mathrm{CuSO}_{4} \cdot 5 \mathrm{H}_{2} \mathrm{O}$ 3.95, $\mathrm{Co}\left(\mathrm{NO}_{3}\right)_{2} \cdot 6 \mathrm{H}_{2} \mathrm{O} 0.2$ and EDTA 500 , was used as a test plant for the initial screening for bioherbicidal potential, using a $1-5$ index ( $5=$ complete inhibition, $0=$ no inhibition).

Chlorella bioassay. A kind of alga, chlorella (Chlorella regularis) was also used for the initial screening for chlorophyll biosynthesis inhibitor. The stocking culture of C. regularis was grown on Arnon's A5 medium ( $\mathrm{pH}$ 6.5) filled with $1 \mathrm{ml}$ Arnon's A5 solution consisting of $\left(\mathrm{g} \mathrm{L}^{-1}\right)$ $\mathrm{KH}_{2} \mathrm{PO}_{4} 1, \mathrm{MgSO}_{4} \cdot 7 \mathrm{H}_{2} \mathrm{O} 1$, and $\mathrm{FeSO}_{4} \cdot 7 \mathrm{H}_{2} \mathrm{O} 0.005$ at $25^{\circ} \mathrm{C}$ under illumination of intensity of 2,000 Lux for 8 days. The flask for stocking liquid culture of $C$. regularis was shaken reciprocally at 120 strokes per minute. Pouring the stocking solution into the plate, the solution was mixed with YGA medium consisting of $\left(\mathrm{g} \mathrm{L}^{-1}\right)$ yeast extract 5 , glucose 20 , and agar 20.

Seed germination bioassay. A third evaluation of herbicidal potential was performed using an in vitro seed germination bioassay on blotter in Petri dishes against ladino clover and white clover (Trifolium repens L.) seeds. For inoculation, conidia and mycelia were suspended in sterile water, adjusted to $1 \times 10^{6}$ and $2.5 \times 10^{7}$ bodies per $\mathrm{mL}$, and $2 \mathrm{ml}$ was poured on the blotter $(8 \mathrm{~cm})$ plated with $10-20$ seeds, and then incubated prior to examination for 7-10 days under light (2000 Lux) at $25^{\circ} \mathrm{C}$.

In vivo herbicidal activity. A fourth evaluation of in vivo herbicidal activity of M. roridum F0252 against 15 plants was performed both in pre- and post-plant emergence by a whole plant spray method (Lee et al., 2003). Bioherbicidal activity of the ground culture broth containing conidia and mycelial fragments and an ethyl acetate (EtOAc) extract of 
the broth were tested on pots (surface area $\times$ height $=350$ $\mathrm{cm}^{2} \times 8 \mathrm{~cm}$ ) containing 15 plants using a hand sprayer, according to the method by Lee et al. (2003). The 13 weedy plants tested against were velvetleaf (Abutilon avicennae), Indian jointvetch (Aeschynomene indica), cheatgrass (Agropyron smithii), bindweed (Calystegia japonica), large crabgrass (Digitaria sanguinalis), barnyardgrass (Echinochloa crus-galli), monochoria (Monochoria vaginalis), fall panicum (Panicum dichotomiflorum), arrowhead (Sagittaria pygmaea), bulrush (Scirpus juncoides), black nightshade (Solanum nigrum), clover (Trifolium repens), and cocklebur (Xanthium strumarium), and the two crops represented were rice (Oryza sativa) and sorghum (Sorghum bicolor). The fungal culture broth and crude extract were separately solubilized into water containing $0.2 \%$ Tween 20 and then $14 \mathrm{~mL}$ was sprayed onto the plants. The herbicidal activities (control values) were evaluated visually 4 and 14 days after treatment on the basis of morphological and physiological symptoms by the following mean percent scores of two replicates ( 0 , no activity; $10-30$, slight activity; 40-60, moderate activity; 70-90, strong activity; 100 , complete death of the plant).

Fungal growth. As a basic medium for mycelial growth of M. roridum F0252, 2\% malt extract agar (MEA, Difco) was used. Water activity $\left(\mathrm{a}_{\mathrm{w}}\right)$ of the basic medium was $0.995 \mathrm{a}_{\mathrm{w}}$ and was modified with glycerol to produce media with other water activity values: $0.95,0.964$, and $0.982 \mathrm{a}_{\mathrm{w}}$. Other media such as potato dextrose agar (PDA, Difco), yeast extract-peptone-soluble starch (YPSS), natural wheat bran (NWB), and natural seeds of ladino and white clovers (Trifolium repens) were also used as a liquid or solid-liquid media. Mycelial growth of the strain on MEA was measured 8 days after inoculation. For inoculum preparation, sporulation was induced by slightly scratching a mycelial mat of M. roridum F0252 grown on PDA for 2 weeks and by changing the incubation temperature (from 15 to $25^{\circ} \mathrm{C}$ ). Conidia were collected from Petri plates using a small soft brush, suspended in sterile water, and then the suspension used as inoculum.

Carbon-sources utilization. Experiments regarding the nutritional utilization of 95 carbon sources by the strain $M$. roridum F0252 were performed on BIOLOG (GN MicroPlate, BIOLOG Inc., CA, USA) plates under different $a_{w}$ and temperature conditions according to the method by Lee and Magan (1999) and Wilson and Lindow (1994). Spores obtained from MEA medium were suspended in sterile water, centrifuged, washed, and centrifuged again in a 0.25 M 2-(N-morpholino) ethanosulfonic acid (MES, Sigma Chemical Co., USA) solution buffered to $\mathrm{pH}$ 5.5. The solutions were modified to $0.95,0.96$ and $0.98 \mathrm{a}_{\mathrm{w}}$ values using sodium chloride. The final spore concentration of the suspension was about $10^{7}$ spores per $\mathrm{mL}$ and $100 \mu \mathrm{L}$ of suspension was added to each test plate well. The BIOLOG plates were incubated at 18,25 and $30^{\circ} \mathrm{C}$ for 2 weeks prior to examination for the utilization of 95 carbon sources. The ability of the fungus to utilize carbon sources in plate wells was investigated under stereo-microscope.

\section{Results}

Fungal identification of F0252. The fungal strain, Myrothecium sp. F0252 was identified as Myrothecium roridum based on morphological characteristics and its $18 \mathrm{~S}$ ribosomal DNA sequence. On all media used in this study, the fungus characteristically produced sporodochia which were cushionlike, sometimes possessing hyaline and white margins. The conidiophores were subhyaline to colored, repeatedly branched, and bearing terminal conidia. In culture, sporodochia were sessile, up to $2 \mathrm{~mm}$ in diameter, and often confluent. Spore masses were initially viscous and green and later hard and black. Conidia were cylindrical with rounded ends, colorless to pale olive green to black when in mass, and mostly $6-8 \mu \mathrm{m}$ by $1.5-2.5 \mu \mathrm{m}$. The fungus matched Myrothecium roridum Tode ex. Fr. based on the morpho-

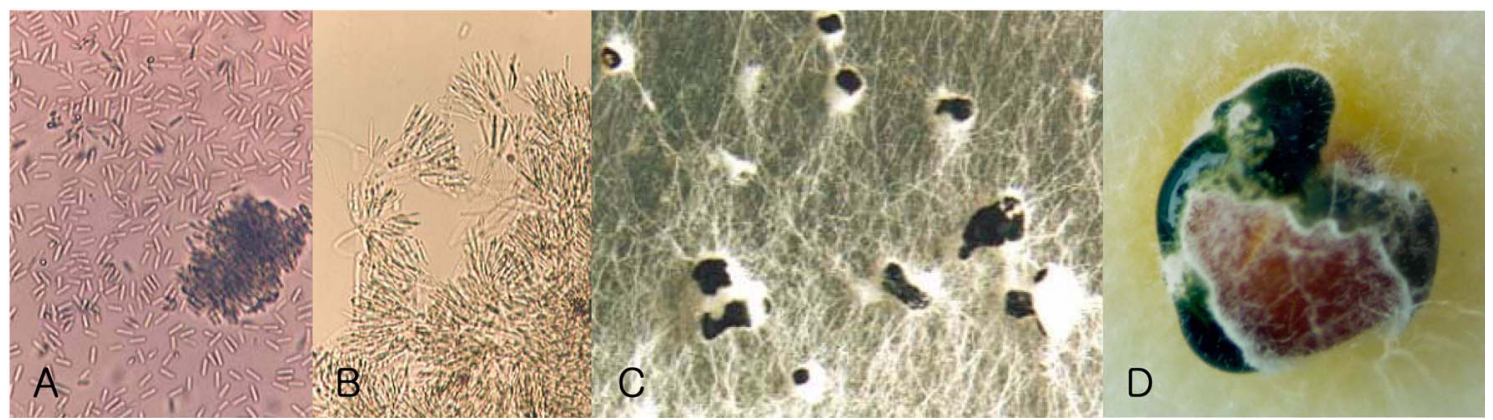

Fig. 1. Morphology of M. roridum F0252. Phialoconidia $(A, \times 400)$, phialides $(B, \times 400)$, sporodochia $(C, \times 40)$ covered with white mycelia formed on PDA medium, and seed coat (D) of ladino clover covered with M. roridum F0252 on moist filter paper in Petri dish 96 hrs after inoculation. 


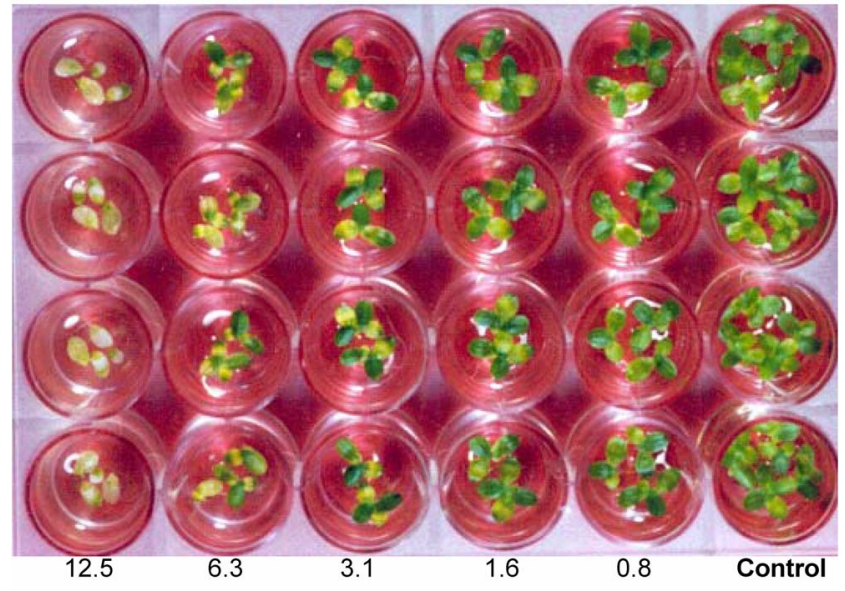

Fig. 2. Effect of crude ethyl acetate extract of M. roridum F0252 on growth of duckweed (Lemna paucicostata) in the level of 12.5, 6.3, 3.1, 1.6, 0.8 and 0 (control) $\mu \mathrm{g} \mathrm{mL}^{-1} 72 \mathrm{hrs}$ after treatment.

logical, culture characteristics, and molecular methods previously described (Fig. 1). When the sequences of the isolates were compared with related species retrieved from GenBank, the intraspecific DNA homologies ranged from $99-100 \%$ identical (data not shown).

In vitro herbicidal activity. Culture broth and crude EtOAc extract of the fungal strain were highly active against duckweed (Lemna paucicostata) and chlorella (Chlorella regularis) on Petri dishes, and the herbicidal activity against chlorella was present even with culture broth at $32 \mathrm{X}$ dilution, showing not only that this strain had
Table 1. Inhibitory effect of spore suspension of $M$. roridum F0252 on seed germination and seedling growth of ladino and white clovers

\begin{tabular}{crrrr}
\hline \hline \multirow{2}{*}{ Concentrations } & \multicolumn{2}{c}{ Ladino clover } & \multicolumn{2}{c}{ White clover } \\
\cline { 2 - 5 } & \multicolumn{1}{c}{ Hypocotyl } & \multicolumn{1}{c}{ Root } & Hypocotyl & \multicolumn{1}{c}{ Root } \\
\hline $6.5 \times 10^{6}$ & $3.5 \pm 1.8^{\mathrm{a}}$ & $3.8 \pm 1.8$ & $2.6 \pm 0.7$ & $3.2 \pm 1.8$ \\
$2.5 \times 10^{7}$ & $2.4 \pm 1.1$ & $2.1 \pm 1.1$ & $2.5 \pm 1.2$ & $1.6 \pm 0.5$ \\
Control $\left(\mathrm{H}_{2} \mathrm{O}\right)$ & $13.0 \pm 1.7$ & $9.1 \pm 1.4$ & $11.1 \pm 2.1$ & $11.5 \pm 1.3$ \\
\hline
\end{tabular}

${ }^{a}$ The lengths (average $\pm \mathrm{SD}, \mathrm{mm}$ ) of seedlings on moist blotter in Petri dish were measured 7 days after inoculation.

high activity, but also that these in vitro assays were very effective for initial screenings (data partly shown). EtOAc extract of the active strain also showed moderate phytotoxicity against duckweed even at a lowered extract concentration of $1.6 \mu \mathrm{g}$ per $\mathrm{mL}$, especially causing withering and discoloration within 2-3 days (Fig. 2). The inhibitory effect of spore suspension on seed germination and seedling growth of clovers varied with the fungal spore concentration in the Petri dishes. Seed germination and early seedling growth of clovers were gradually inhibited up to the level of $6 \times 10^{6}$ spores per $\mathrm{mL}$, but completely inhibited at the highest concentration, $2.5 \times 10^{7}$ spores per $\mathrm{mL}$, causing an abnormal withering and inhibition of growth compared to the control plants (Table 1 and Fig. 3). Clover seedling growth (by length) was reduced to approx. 1/3-1/6 of the growth of the controls (Table 1), while radishes were slowly, but considerably inhibited at the concentration of $>2.5 \times 10^{7}$ spores per $\mathrm{mL}$ (data not shown).

In vivo herbicidal activity. Culture broth showed $95-100 \%$

Table 2. In vivo herbicidal activity of culture broth and crude ethyl acetate extract of $M$. roridum F0252 against weedy plants

\begin{tabular}{|c|c|c|c|c|}
\hline \multirow{3}{*}{ Scientific name } & \multirow{3}{*}{ Common name } & \multicolumn{3}{|c|}{ Control values after $(\%)^{\mathrm{a}}$} \\
\hline & & \multirow{2}{*}{$\frac{\text { Culture broth }}{14 \text { days }}$} & \multicolumn{2}{|c|}{ EtOAc extract } \\
\hline & & & 4 days & 14 days \\
\hline Abutilon avicennae & Velvetleaf & 20 & 30 & 100 \\
\hline Aeschynomene indica & Indian jointvetch & 95 & 95 & 100 \\
\hline Agropyron smithii & Cheatgrass & 30 & 95 & 100 \\
\hline Calystegia japonica & Bindweed & 100 & 70 & 100 \\
\hline Digitaria sanguinalis & Large crabgrass & 70 & 100 & 100 \\
\hline Echinochloa crus-galli & Barnyardgrass & 40 & 100 & 100 \\
\hline Monochoria vaginalis & Monochoria & 100 & 100 & 100 \\
\hline Oryzae sativa & Rice & $\mathrm{NE}$ & ND & ND \\
\hline Panicum dichotomiflorum & Fall panicum & 95 & 80 & 100 \\
\hline Sagittaria pygmaea & Arrow head & NE & ND & 80 \\
\hline Scirpus juncoides & Bulrush & 30 & ND & 30 \\
\hline Solanum nigrum & Black nightshade & 95 & 80 & 95 \\
\hline Sorghum bicolor & Sorghum & 40 & 95 & 100 \\
\hline Trifolium repens & Clover & 100 & ND & 100 \\
\hline Xanthium strumarium & Cocklebur & 100 & 95 & 100 \\
\hline
\end{tabular}

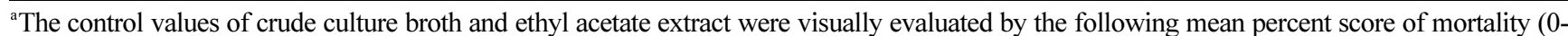
$100 \%) 4$ and 14 days after treatment: 0 , no activity; $10-30$, slight activity; $40-60$, moderate activity; 100 , complete death on pots $\left(350 \mathrm{~cm}^{2}\right) .{ }^{b} \mathrm{NE}$, no herbicidal effect; ND, no determination. 


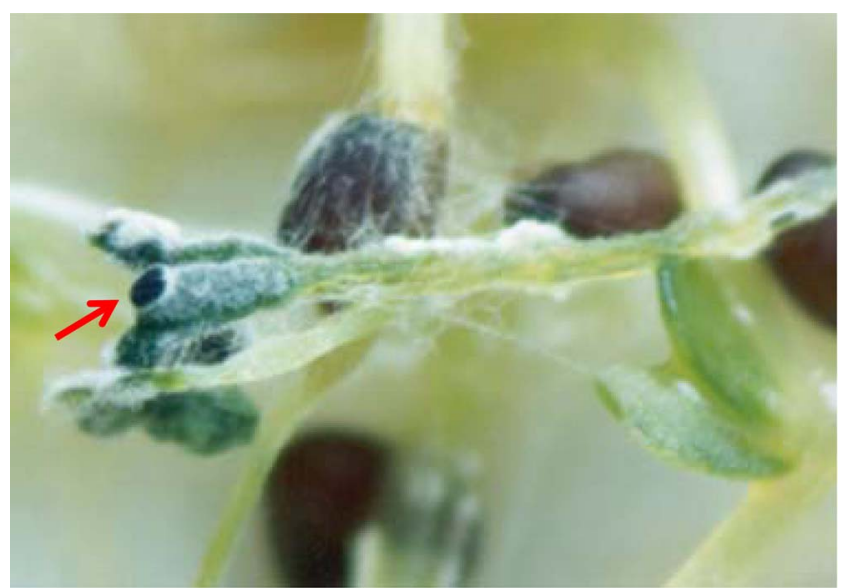

Fig. 3. Infection of M. roridum F0252 on seedling of ladino clover which is covered with mycelia and sporodochia. Arrow shows the sporodochia of the fungus on cotyledon.

bioherbicidal activity to 7 weeds including Aes. indica, $C$. japonica, $M$. vaginalis, $P$. dichotomiflorum, Sol. nigrum, $T$. repens, and $X$. strumarium, $70 \%$ activity to $D$. sanguinalis, and low or no activity to Abu. avicennae, Agr. smithii, E. crus-galli, O. sativa, Sag. pygmaea, Sci.juncoides, and Sor. bicolor (Table 2). These results show that M. roridum F0252 can be used as a selective bioherbicide for rice weed control. Herbicidal effects varied according to plant species and exposure time, and the symptoms were various, including water-soaked oval spots on the infected leaves, chlorosis, and necrosis. The crude EtOAc extract showed much higher in vivo herbicidal activity (completely inhibited at dose of approx. $500 \mu \mathrm{g}$ freeze-dried per $\mathrm{mL}$ ) than the culture broth, although there was a similar herbicidal pattern exhibited 3 days after dosing was applied. The EtOAc extract showed a complete and broad-herbicidal activity against Agr. smithii, D. sanguinalis, E. crus-gallii, Sor. bicolor, $T$. repens, and $X$. strumarium within 3-4 days. However, the complete herbicidal effect of the extract on Abu. avicennae was shown after 14 days. Regarding Sag. pygmaea, there was little herbicidal effect by the culture broth but moderate effect by extract. These results showed that $M$. roridum might be used as a seed germination inhibitor to control several problematic weeds in Korea.

Fungal growth and C-sources utilization. Mycelial growth of $M$. roridum on MEA tended to increase with increasing $\mathrm{a}_{\mathrm{w}}$, and there was significantly reduced growth at $0.95 \mathrm{a}_{\mathrm{w}}$ as a common field fungus (Fig. 4). Although the mycelial growth of the fungus was best at $25^{\circ} \mathrm{C}$, growth was similar between 18 and $30^{\circ} \mathrm{C}$.

The nutritional utilization pattern of M. roridum F0252 on GN MicroPlate was found to vary with environmental factors such as water activity $\left(\mathrm{a}_{\mathrm{w}}\right)$ and temperature, supply-

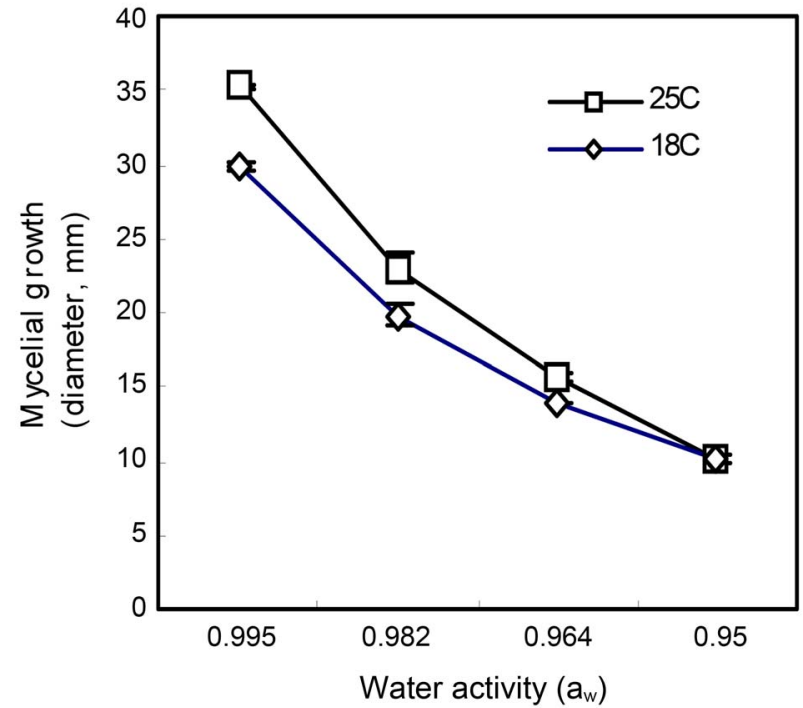

Fig. 4. Effect of temperature and water activity $\left(a_{w}\right)$ on mycelial growth of $M$. roridum $\mathrm{F} 0252$ on MEA.

ing good, basic information for proper cultivation and formulation. The number of C-sources utilized by the fungus showed slight difference between 0.995 and 0.982 , and ranged $60-70$, but was significantly reduced at $0.95 \mathrm{a}_{\mathrm{w}}$ (Fig. 5). Interestingly, the number of $\mathrm{C}$-sources utilized by the fungus at lowered water availability levels $\left(0.95 \mathrm{a}_{\mathrm{w}}\right)$ was approx. 10 at $25^{\circ} \mathrm{C}$, but almost no $\mathrm{C}$-sources utilized at $18^{\circ} \mathrm{C}$ and at $30^{\circ} \mathrm{C}$.

\section{Discussion}

Through in vitro and in vivo screening for bioherbicide activity, a hyphomycete fungus with a potent herbicidal potential has been selected. Out of 1,000 isolates tested, $M$. roridum $\mathrm{F} 0252$ strain was the most active agent against weeds. Thus far, the species M. roridum Tode ex Fries, a common soil fungus, has been reported to be pathogenic to a number of plant species. Walker and Tilley (1997) suggested that some Myrothecium species might be used as broad-spectrum bioherbicides against several weeds. However, there is little information about bioherbicidal activity against various weeds in vivo. Most of Myrothecium in these studies were isolated from their own hosts and belonged to M. verrucaria. The experimental results presented here showed that $M$. roridum $\mathrm{F} 0252$ can be used as a broad-spectrum mycoherbicide and/or as a seed germination inhibitor to control several problematic weeds in Korea. Interestingly, the fungus showed low or no activity against some crop plants including $O$. sativa and Sor. bicolor showing that the agent can be used as a selective mycoherbicide in rice or wheat fields.

On the other hand, the most important characteristic of 


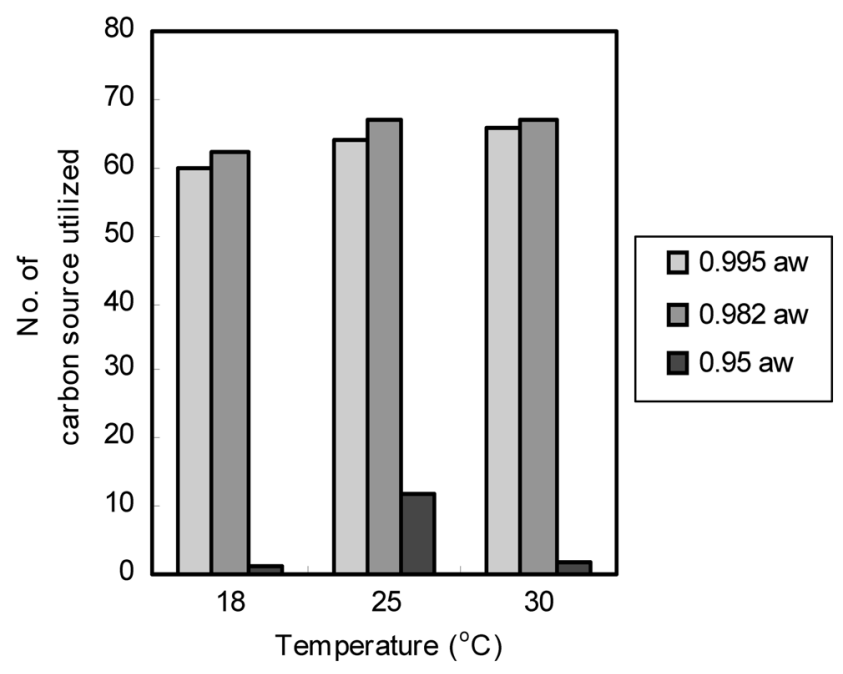

Fig. 5. Effect of water activity and temperature on nutritional utilization of 95 carbon sources of M. roridum F0252 on GN MicroPlate.

Myrothecium was its exhibited seed germination inhibition. When the seeds and early seedlings of ladino or white clovers (T. repens), were inoculated with spores of $M$. roridum F0252, the seed germination and seedling growth of the clovers were gradually and completely inhibited as the level spores reached $6.5 \times 10^{6}$ spores per $\mathrm{mL}$ in Petri dish tests (Table 1 and Fig. 3). In addition, the EtOAc extract showed much higher herbicidal activity to clover and radish seedlings at dose of approx. $500 \mu \mathrm{g}$ per $\mathrm{mL}$ (data not shown). By virtue of the mounds of dark black spores (sporodochia) that can develop on infected tissue, the thousands of spores contained within these structures, and the small sized spores that can be easily spread between plants by splashing water, this fungal agent has a significant potential as a BCA.

The bioherbicidal activities of this fungus may be mainly due to a phytotoxin or other toxic metabolites (Drake, 1980; Durbin, 1981). Verrucarin A, a germination inhibitor of Orobanche crenata, has been isolated from $M$. verrucaria (Alb. \& Schwein.) Ditmar (Drake, 1980; El-Kassas et al., 2005; Harper and Lynch, 1981). Our results showed that the EtOAc extract (containing no viable spores) also showed a strong herbicidal activity both in vitro and in vivo, showing a possible metabolic effect. Bioherbicidal metabolites are also being studied as possible herbicides or herbicidal adjuvants to develop BCAs that are selective, easily degradable, and environmentally friendly.

The efficacy of biocontrol may be enhanced by combinatory use of phytotoxins with herbicides (Vurro et al., 2001). Two verrucarins from M. roridum has been isolated and characterized (Schoettlera et al., 2006). Macrocyclic trichothecenes are undetectable in kudzu (Pueraria montana) plants treated with $M$. verrucaria. It has been known that trichothecenes exhibit varied biological activities such as antifungal, cytotoxic, and phytotoxic effects (Cunfer and Lukezic, 1979; Kuti et al., 1989). The trichothecenes are normally divided into two broad categories: non-macrocylic trichothecenes (e.g. T-2 toxin, diacetoxyscirpenol, and deoxynivalenol) and macrocylic trichothecenes such as the verrucarins and roridins which are mainly produced by Myrothecium species (Cutler and Jarvis, 1985). Kuti et al. (1989) mentioned the possible involvement of a pathogenproduced trichothecenes, such as verrucarins and roridins from Myrothecium, in leaf spot of muskmelon. A combination of two pathogens, Cercospora and Myrothecium species, is being evaluated as a potential bioherbicide for the water hyacinth, Eichhornia crassipes (Mart.) SolmsLaub. under field conditions (Charudattan, 2001).

Boyette and Abbas (2001) reported that the bioherbicide $M$. verrucaria obtained from sicklepod eliminated common purslane, horse purslane, ground spurge, and spotted spurge which have long been serious problem weeds among commercially grown tomatoes. Fungi can successfully infect hosts whose tissues are wounded or exposed to certain environmental conditions, such as excessive humidity (Fergus, 1957). McLean and Sleeth (1961) reported that symptoms of pathogenicity of the fungus on muskmelon included leaf spots and Cunfer and Lukezic (1970) discussed Myrothecium toxin and its possible role in plant leaf spot.

In this study, the antimicrobial, antialgal and insecticidal activities of the culture broth were also investigated by the paper disc method. Little activity was observed against Gram negative and positive bacteria: Escherichia coli KCTC1924, Bacillus subtilis KCTC1914, Salmonella typhimurium KCTC1926, Staphylococcus aureus KCTC1916, and Staphylococcus aureus KCTC1928; two fungi, Aspergillus flavus HBL-AF1 and Candida albicans KCTC1940; and five insects, including brown plant hopper (Nilapavata lugens), tobacco cutworm (Spodoptera litura), green peach aphid (Myzus persicae), two spotted spider (Tetranychus urticae), and diamondback moth (Plutella xylostella) (data not shown).

Formulation, growth media, and the application method are important determinants in the efficacy of $M$. verrucaria on kudzu seedlings (Hoagland et al., 2007). So far, there have been several studies on the formulations and their applications of Myrothecium species to fields and greenhouses, and the interaction between bioherbicide and herbicide (Boyette et al., 2008; Hoagland et al., 2007; Vincent et al., 1999). According to Boyette et al. (2007), when $M$. verrucarium was applied alone, the post-emergence provided no control of purslanes and spurges, but when formulated with a surfactant, Silwet L-77, caused 85$95 \%$ and $90-95 \%$ mortality to purslanes and spurges weed 
species, respectively. Silwet L-77 (0.1\%) also increased infection by $M$. roridum, and the combination of SeaSpen (a gel-forming polysaccharide extracted from red seaweed) at $0.5 \%$ and oil at $10 \%$ enhanced infection by Plectosphaerella cucumerina, reducing each isolate's dew point requirements for infection.

In this study, utilization of basic carbon sources by $M$. roridum F0252 was investigated for proper formulation. In the present experiments, surfactants were not applied to the screenings. If the present carbon utilization results were to be applied to the formulation of M. roridum F0252, the efficacy of the fungal culture may be increased. Our study was only focused on the primary screening for biocontrol of weeds using fungal cultures. Thus, further studies on the ecophysiology of the active fungus, the formulation for improving efficacy as a bioherbicide and the isolation of active compounds for study on mode of action are needed in the future. In order to improve the biocontrol efficacy of the agent, further studies on the appropriate formulation as well as the combinatory use of these microbes with metabolites or herbicides are needed.

\section{Acknowledgements}

This study was supported in part by a grant (20070301034004) from BioGreen21 program, Rural Development Administration to HBL and JCK; This study was also supported in part by Technology Development Program for Agriculture and Forestry, Ministry for Agriculture, Forestry and Fisheries, Korea to CJK.

\section{References}

Abbas, H. K., Tak, H., Boyette, C. D., Shier, W. T. and Jarvis, B. B. 2001. Macrocyclic trichothecenes are undetectable in kudzu (Pueraria montana) plants treated with a high-producing isolate of Myrothecium verrucaria. Phytochemistry 58: 269-276.

Boyette, C. D. and Abbas, H. K. 2001. New bioherbicides whacks weeds. In: Vegetable Production \& Marketing News, ed. by F. J. Dainello, pp. 9-10.

Boyette, C. D., Hoagland, R. E. and Abbas, H. K. 2007. Evaluation of the bioherbicide Myrothecium verrucaria for weed control in tomato (Lycopersicon esculentum). Biocontrol Sci. Techn. 17:171-178.

Boyette, C. D., Hoagland, R. E., Weaver, M. A. and Reddy, K. N. 2008. Redvine (Brunnichia ovata) and trumpercreeper (Campsis radicans) controlled under field conditions by a synergistic interaction of the bioherbicide, Myrothecium verrucaria, with glyphosate. Weed Biol. Manag. 8:39-45.

Boyette, C. D., Walker, H. L. and Abbas, H. K. 2002. Biological control of kudzu (Pueraria lobata) with an isolate of Myrothecium verrucaria. Biocontrol Sci. Techn. 12:75-82.
Butt, T. M., Jackson, C. and Magan, N. 2001. Introduction-fungal biological control agents: progress, problems and potential. In: Fungi as biocontrol agents, Progress, Problems and Potential, CABI Publishing, UK.

Charudattan, R. 1991. The mycoherbicide approach with plant pathogens. In: Microbial control of weeds, ed. by D. O. TeBeest, pp. 24-57. Chapman and Hall, New York, USA.

Charudattan, R. 2001. Biological control of water hyacinth by using pathogens: Opportunities, challenges, and recent developments. In: Biological and integrated control of water hyacinth, Eichhornia crassipes, ed. by M. H. Julian, M. P. Hill, T. D. Center and D. Jianquing, p. 102. ACIAR Proceedings.

Chase, A. R. and Poole, R. T. 1984. Development of Myrothecium roridum leaf spot of Dieffenbachia maculate 'perfection' at various temperature. Plant Dis. 68:488-490.

Christy, A. L., Herbst, K. A., Kostka, S. J., Mullen, J. P. and Carlson, P. S. 1992. Synergizing weed biocontrol agents with chemical herbicides. In: Pest control with enhanced environmental safety, ed. by S. O. Duke, J. J. Menn and J. R. Plimmer, pp. 87-100. Washington DC: American Chemical Society, USA.

Clarke, T. C., Shetty, K. G., Jayachandran, K. and Norland, M. R. 2007. Myrothecium verrucaria-a potential biological control agent for the invasive old world climbing fern (Lygodium microphyllum). BioControl 52:399-411.

Cunfer, B. M. and Lukezic, F. L. 1970. A toxin from Myrothecium and its possible role in Myrothecium leaf spot of red clover. Phytopathology 60:341-344.

Cutler, H. G. and Jarvis, B. B. 1985. Preliminary observation on the effects of macrocylic trichothecenes on plant growth. Environ. Exp. Bot. 25:115-128.

Defago, G., Ammon, H. U., Cagan, L., Draeger, B., Greaves, M. P, Guntli, D., Hoeke, D., Klimes, L., Lawrie, J., Moenne-Loccoz, Y., Nicolet, B., Pfirter, H. A., Tabacchi, R. and Toth, P. 2001. Towards the biocontrol of bindweeds with a mycoherbicide. BioControl 46:157-173.

Domsch, K. H. and Gams, W. 1980. Compendium of soil fungi. Myrothecium, Vol. 1:483-484. Academic Press, London, UK.

Drake, G. N. 1980. Effect of Myrothecium roridum on the germination of cotton seeds. Indian Phytopath. 33:591-593.

Durbin, R. D. 1981. Toxins in plant disease. Academic Press, New York, USA.

El-Kassas, R., Karam El-Din, Z., Beale, M. H., Ward, J. L. and Strange, R. N. 2005. Bioassay-led isolation of Myrothecium verrucaria and verrucarin A as germination inhibitors of Orobanche crenata. Weed Res. 45:212-219.

Ellis, M. B. 1971. Dematiaceous Hyphomycetes. Myrothecium, pp. 552-556. CMI, KEW, UK.

Evans, H. C., Mike, P. and Watson, A. K. 2001. Fungal biocontrol agents of weeds. In: Fungi as biocontrol agents. Progress, problems and potential, ed. by T. M. Butt, C. Jackson and N. Magan, CABI Publishing, UK.

Fergus, C. L. 1957. Myrothecium roridum on gardenia. Mycologia 49:124-127.

Harper, S. H. and Lynch, J. M. 1981. Effects of fungi on barley seed germination. J. Gen. Microbiol. 122:55-60. 
Hoagland, R. E., Boyette, C. D. and Abbas, H. K. 2007. Myrothecium verrucaria isolates and formulations as bioherbicide agents for kudzu. Biocontrol Sci. Tech. 17:721-731.

Kathleen, I., Anderson, A. and Steven, G. and Hallett, B. 2004. Herbicidal spectrum and activity of Myrothecium verrucaria. Weed Sci. 52:623-627.

Kuti, J. O., Ng, T. J. and Bean, G. A. 1989. Possible involvement of a pathogen-produced trichothecene metabolite in Myrothecium leaf spot of muskmelon. Physiol. Mol. Plant Pathol. 34:41-54.

Lee, H. B., Kim, C. J., Kim, J. S., Hong, K. S. and Cho, K. Y. 2003. A bleaching herbicidal activity of methoxyhygromycin (MHM) produced by an actinomycete strain Streptomyces sp. 8E-12. Lett. Appl. Microbiol. 36:387-391.

Lee, H. B. and Magan, N. 1999. Environmental factors and nutritional utilization patterns affect niche overlap indices between Aspergillus ochraceus and other spoilage fungi. Lett. Appl. Microbiol. 28:300-304.

Lee, H. B., Park, J. Y. and Jung, H. S. 2005. Identification, growth and pathogenicity of Colletotrichum boninense causing leaf anthracnose on Japanese spindle tree. Plant Pathol. J. 21:2732.

Lee, H. B., Park, J. Y., Jung, H. S. and Summerbell, R. C. 2006. Phaeomoniella zymoides and Phaeomoniella pinifoliorum spp. nov., new acid-tolerant epiphytic fungi isolated from pine needles in Korea. Mycologia 98:598-611.

Mackay, W. A., Ng, T. J. and Hammerschlag, F. A. 1994. Cucumis melo L. callus response to toxins produced by Myrothecium roridum Tode ex. Fries. J. Amer. Soc. Hort. Sci. 119:356-360.

Muller-Scharer, H., Scheepens, P. C. and Greaves, M. P. 2000. Biological control of weeds in European crops: recent achievement and future work. Weed Res. 40:83-98.

McLean, D. M. and Sleeth, B. 1961. Myrothecium rot of cantaloupes. Plant Dis. Rep. 45:728-729.

Preston, N. G. 1961. Observations on the genus Myrothecium, III The cylindrical-spored species of Myrothecium known in Britain. Trans. Brit. Mycol. Soc. 44:31-41.

Quimby, P. C., DeLoach, C. J., Wineriter, S. A., Goolsby, J. A.,
Sobhian, R., Boyette, C. D. and Abbas, H. K. 2003. Biological control of weeds: selected USDA-ARS case studies. Pest Manag. Sci. 59:671-680.

Rosskopf, E. N., Charudattan, R. and Kadir, J. B. 1999. Use of plant pathogens in weed control. In: Handbook of biological control, ed. by T. W. Fisher, T. S. Bellows, L. E. Caltagirone, D. L. Dahlsten, C. Huffaker and G. Gordh, pp. 891-918. Academic Press, San Diego, California, USA.

Schoettlera, S., Bascopeb, M., Sternerb, O. and Ankea, T. 2006. Isolation and characterization of two verrucarins from Myrothecium roridum. Z. Naturforsch 61: 309-314.

TeBeest, D. O. 1991. Ecology and epidemiology of fungal plant pathogens studied as biological control agents of weeds. In: Microbial control of weeds, ed. by D. O. TeBeest, pp. 97-114. Chapman and Hall, New York, USA.

Vincent, A. C. and Charudattan, R. 1999. Effects of formulations of Myrothecium roridum Tode ex. Fr. and Cercospora rodmanii Conway on water hyacinth (Eichhornia crassipes [Mart.] Solms-Laub.) under greenhouse and field conditions. WSSA Abstracts 39:71-72.

Vurro, M., Zonno, M. C., Evidente, A., Andolfi, A. and Montemurro, P. 2001. Enhancement of efficacy of Ascochyta caulina to control Chenopodium album by use of phytotoxins and reduced rates of herbicides. Biol. Control 21:182-190.

Walker, H. L. and Tilley, A. M. 1997. Evaluation of an isolate of Myrothecium verrucaria from sicklepod (Senna obtusifolia) as a potential mycoherbicide agent. Biol. Control 10:104-112.

Watson, A. K. 1991. The classical approach with plant pathogens. In: Microbial control of weeds, ed. by D. O. TeBeest, pp. 3-23. Chapman and Hall, New York, USA.

Wilson, M. and Lindow, S. E. 1994. Coexistence among epiphytic bacterial populations mediated through nutritional resource partitioning. Appl. Environ. Microbiol. 60:4468-4477.

Woodburn, A. 1995. Cotton: the crop and its agrochemicals market. Allan Woodburn Assoc. Ltd., Edimburgh, UK.

Yang, S. M. and Brenner, D. 1997. Virulence and host range of three species of Myrothecium on Amaranthus spp. ARS USDA, TEKTRAN, USA. 